\title{
Differential Dopamine Receptor D4 Allele Association with ADHD Dependent of Proband Season of Birth
}

K.J. Brookes, ${ }^{1 *}$ B. Neale, ${ }^{1}$ X. Xu, ${ }^{1}$ A. Thapar, ${ }^{2}$ M. Gill, ${ }^{3}$ K. Langley, ${ }^{2}$ Z. Hawi, ${ }^{3}$ J. Mill, ${ }^{1}$ E. Taylor, ${ }^{1}$ B. Franke, ${ }^{7}$ W. Chen, ${ }^{1}$ R. Ebstein, ${ }^{12}$ J. Buitelaar, ${ }^{7}$ T. Banaschewski, ${ }^{6}$ E. Sonuga-Barke, ${ }^{10}$ J. Eisenberg, ${ }^{9}$ I. Manor, ${ }^{5}$ A. Miranda, ${ }^{8}$ R.D. Oades, ${ }^{4}$ H. Roeyers, ${ }^{13}$ A. Rothenberger, ${ }^{6} \mathrm{~J}$. Sergeant, ${ }^{11}$ H.C. Steinhausen, ${ }^{14}$ S.V. Faraone, ${ }^{15}$ and P. Asherson ${ }^{1}$

\section{American Journal of Medical Genetics Part B, 147B, 94-99.}

This is the reformatted manuscript submitted - prior to publication in its final form at DOI: 10.1002/ajmg.b.30562

1 MRC Social Genetic Developmental and Psychiatry Centre, Institute of Psychiatry, London, UK

2 Department Psychological Medicine, School of Medicine, Cardiff University, Heath Park, Cardiff, UK

3 Department of Psychiatry, Trinity Centre for Health Sciences, St. James's Hospital, Dublin, Ireland

4 University Clinic for Child and Adolescent Psychiatry, Essen, Germany

5 Geha MHC, Petach-Tikva, Israel

6 Child and Adolescent Psychiatry, University of Göttingen, Göttingen, Germany

7 Department of Psychiatry, Radboud University Nijmegen Medical Center, Nijmegen, The Netherlands

8 Department of Developmental and Educational Psychology, University of Valencia, Valencia, Spain

9 ADHD Clinic, Geha Mental Health Center, Petak Tikvah, Israel

10 School of Psychology, University of Southampton, Highfield, Southampton, UK

11 Vrije Universiteit, De Boelelaan, Amsterdam, The Netherlands

$12 \mathrm{~S}$. Herzog Memorial Hospital, Jerusalem, Israel

13 Ghent University, Dunantlaan 2, Ghent, Belgium

14 Department of Child and Adolescent Psychiatry, University of Zurich, Zurich, Switzerland

15 Child and Adolescent Psychiatry Research, SUNY Upstate Medical University, Syracuse, New York, USA

*Correspondence to: K.J. Brookes, MRC Social Genetic Developmental Psychiatry, Institute of Psychiatry, De Crespigny Park, London SE5 8AF, UK. E-mail: k.brookes@iop.kcl.ac.uk

Key Words: attention deficit hyperactivity disorder (ADHD); season of birth;

Acknowledgments: We thank all the families who kindly participated in this research. Research was funded by the MRC and Wellcome Trust in the UK, the Health Research Board and Molecular Medicine Centre in Dublin The IMAGE project is supported by NIH grant R01MH62873 to S.V. Faraone. 


\section{Abstract:}

Season of birth (SOB) has been associated with attention deficit hyperactivity disorder (ADHD) in two existing studies. One further study reported an interaction between SOB and genotypes of the dopamine D4 receptor (DRD4) gene. It is important that these findings are further investigated to confirm or refute the findings. In this study, we investigated the SOB association with ADHD in four independent samples collected for molecular genetic studies of ADHD and found a small but significant increase in summer births compared to a large population control dataset. We also observed a significant association with the 7-repeat allele of the DRD4 gene variable number tandem repeat polymorphism in exon three with probands born in the winter season, with no significant differential transmission of this allele between summer and winter seasons. Preferential transmission of the 2-repeat allele to ADHD probands occurred in those who were born during the summer season, but did not surpass significance for association, even though the difference in transmission between the two seasons was nominally significant. However, following adjustment for multiple testing of alleles none of the SOB effects remained significant. We conclude that the DRD4 7-repeat allele is associated with ADHD but there is no association or interaction with SOB for increased risk for ADHD. Our findings suggest that we can refute a possible effect of SOB for ADHD.

\section{INTRODUCTION}

Attention Deficit Hyperactivity Disorder (ADHD) is one of the most prevalent and heritable childhood behavioral disorders. The disorder is characterized by an onset of age inappropriate hyperactivity, impulsivity and inattentiveness before the age of 7 years [American Psychiatric Association, 1994]. Familial risk is established with an estimated sibling risk ratio $(\lambda s=$ risk to siblings of ADHD probands/population risk) for broadly defined ADHD of around threefold to fourfold [Faraone and Doyle, 2000]. Twin studies support the view that genetic factors are the major influence on familial risk with heritability estimates for ADHD symptom scores consistently reported to be in the region of $60-90 \%$ [Thapar et al., 1999]. In general these studies find little evidence of shared environmental influences on familiarity, although the role of environment may still be pivotal acting through mechanisms of gene-environment interaction. Progress in identifying some of the genes involved in ADHD susceptibility has been relatively fruitful over the past decade by screening genetic variants that lie within or close to genes that regulate neurotransmitter systems, particularly dopamine pathways.

One of the first genetic markers reported to be associated with ADHD was the 7-repeat allele of a variable number tandem repeat (VNTR) polymorphism located within exon 3 of the Dopamine D4 Receptor gene (DRD4) [LaHoste et al., 1996]. Subsequent studies replicated this finding although several investigations have also reported negative findings [Faraone et al., 2005]. A recent metaanalysis of available data concluded that there was a small but significant effect of the DRD4 polymorphism on risk for ADHD, with a pooled odds ratio of $1.34(95 \% \mathrm{Cl}$ 1.23-1.45, $p=2^{-12}$ ) [Li et al., 2006].

Although, genetic risk factors are prominent in the development of ADHD, environmental risks are also thought to be important, acting through geneenvironmental interactions. Associated environmental risks for ADHD include low birth weight and maternal use of alcohol and tobacco during pregnancy [Mick et al., 2002a, b]. More recently specific geneenvironment interactions have been reported between genotypes of the 
dopamine transporter gene and maternal use of tobacco during pregnancy on levels of hyperactive-impulsive behavior [Kahn et al., 2003] and maternal use of alcohol on risk for ADHD [Brookes et al., 2006b]. Other research suggests that geneenvironment interactions may increase the rates of antisocial behavior among ADHD probands, rather than having a main effect on risk for ADHD. For example the effects of a catechol-O-methyltransferase (COMT) gene variant and birth weight on the risk of early-onset antisocial behavior in children with ADHD [Thapar et al., 2005].

Another environmental measure that has been investigated is the effect of season of birth (SOB). This association is not well established, with the two studies reporting on this variable in relation to ADHD giving contradictory findings. Mick et al. [1996] concluded that winter birth was associated with ADHD in individuals with learning difficulties, ADHD without psychiatric comorbidities, and ADHD with family history of the disorder. In contrast, an earlier study concluded that spring and summer births increased risk for neurodevelopment disorders, including ADHD [Liederman and Flannery, 1994].

More recently, a report on a potential interaction between SOB and the DRD4 exon 3 polymorphism was published [Seeger et al., 2004]. In a sample of 64 children with comorbid hyperkinetic disorder and conduct disorder (HD + CD) and a matched control sample of 163 children, no main affects of the DRD4 polymorphism or SOB were observed. However, it was found that children with $\mathrm{HD}+\mathrm{CD}$ born in the winter, had significantly fewer 7-repeat alleles (12.5\%) compared to those born in the summer (50\%, $\mathrm{P} 1 / 40.001, \mathrm{OR} 1 / 47)$. This suggested that the 7-repeat allele might be a risk factor for ADHD only for those born in the summer months. The control population exhibited the opposite relationship between SOB and the 7-repeat allele, with those born in winter having a higher allele frequency of 7 -repeat alleles $(43.7 \%)$ in comparison to those being born in the summer (26.1\%, $p=0.019$, OR 2.2).

Discrepancies between the various studies on SOB and ADHD mean that no firm conclusions can be reached at this time. We therefore set out to establish whether in a large collaborative set of clinical ADHD samples there was any evidence for the association of SOB with $A D H D$, and whether SOB interacts with the DRD4 exon 3 VNTR polymorphism in the risk for the disorder. Allowing the confirmation or rejection of the hypothesis that SOB may be a risk factor for ADHD.

In the course of this research, we also considered whether plausible biological arguments could be made for the association between ADHD and SOB. For example SOB might be a proxy for risk factors such as viral infections or amount of daylight exposure during gestation or birth weight [Liederman and Flannery, 1994; Mick et al., 1996]. Those born in the winter spend most of their gestation period in the summer months while conversely those born in the summer have the majority of their gestational time in the winter months. Maternal disorders such as seasonal affective disorder, which might confer prenatal risk, show seasonal variation [Chotai et al., 2003; McGrath et al., 2005; Amons et al., 2006]. In relation to the DRD4, the 7-repeat allele could influence mating behavior in mammals and the associated pattern of mating may be part of a natural cycle with seasonal variation observed in the general population. The dopamine system has been highly implicated in the development of ADHD and it has been discussed that this system is influenced by exogenous factors, such as hours of sunlight, in 
creating an endogenous daily rhythm of dopamine receptor binding, therefore giving credence that hours of daylight could impact on the dopamine system [Naber et al., 1981]. Furthermore, the hormone melatonin is secreted from the pineal gland, in a cyclic rhythm. This rhythm is entrained by the length of daylight the individual is exposed to, and alters the timing of mammalian circadian rhythms [Brzezinski, 1997]. Melatonin is synthesized from serotonin by the enzyme $\mathrm{N}$-acetyl-transferase, which is entrained by the day length cycle, and is more active during dark periods. Therefore, melatonin production is highest during the night and lowest during the day [Reppert and Weaver, 1995]. Melatonin is known to inhibit dopamine release in numerous brain regions including the striatum and dopamine is thought to inhibit the production of melatonin via the DRD4 [Zisapel and Laudon, 1983; Zisapel et al., 1983; Zawilska and Nowak, 1994; Tosini and Dirden, 2000; Zisapel, 2001]. Finally, melatonin can also pass from the mother via the placenta to the fetus, entraining the fetus' circadian rhythm [Goldman, 2003].

We can therefore see that is not difficult to derive biologically plausible explanations for the possible influence of SOB on risk for ADHD and interaction with components of the dopamine system. However, on the basis of the data presented here, we conclude that it is far more likely that there is no effect of SOB on risk for ADHD.

\section{METHODS}

Four independent samples were used, collected by groups in London, Cardiff, Dublin, and the International Multi-centre ADHD Gene (IMAGE) project. The IMAGE project is a multisite site with samples collected in Belgium, England, Germany, Holland, Ireland, Israel, Spain, and Switzerland. Children taking part in these studies were all of white European origin and consisted predominantly of male children with combined subtype ADHD and with DNA available from both parents (Table 1). The individual groups gathered DRD4 exon 3 VNTR genotypes and date of birth information separately and data was sent for this analysis to Keeley Brookes in London. The association findings with DRD4 for these groups have previously been reported [Hawi et al., 2000; Holmes et al., 2000; Mill et al., 2001] with only the large IMAGE sample exhibiting a trend for excess in transmission of the 7-repeat allele from heterozygote parents to their affected offspring [Brookes et al., 2006a]. Clinical procedures for making research diagnoses of ADHD across the different studies used comparable approaches since probands were all ascertained from specialist ADHD clinics and research interviews were the main source of data capture. DSM-IV operational criteria were applied in each case however no direct comparisons were made to check reliability of diagnosis between the different sites and slightly different protocols applied. Detailed descriptions of the sample ascertainment and assessment procedures can be found in the original articles for the DRD4 VNTR [Hawi et al., 2000; Holmes et al., 2000; Mill et al., 2001; Brookes et al., 2006a] and the measures used in each study are listed in Table 1.

In this study, we investigated each sample separately before combining the data into a single set of 1,110 ADHDparent trios. Each cohort was stratified into two subsets dependent on the date of birth of the proband. Following the seasonal definitions used by Seeger et al. [2004] those born between the 22nd March and 22nd September were classified as the summer season group, whereas those born between the $23^{\text {rd }}$ September and the $21^{\text {st }}$ March were classified as the winter season group. Each seasonal subset was analyzed using the 
Table 1:

Description of the 4 independently collected ADHD family data sets utilized in this analysis

\begin{tabular}{|ccccccc|}
\hline Sample & N Trios & \% Males & $\begin{array}{c}\text { Age Range } \\
(\text { Mean/SD })\end{array}$ & $\begin{array}{c}\text { Clinical } \\
\text { Procedure }\end{array}$ & Diagnosis & $\begin{array}{c}\text { Comorbidity } \\
(\text { ODD and } \\
\text { CD }) \%\end{array}$ \\
Landon & 137 & $90 \%$ & $5-15(10.4 / 2.3)$ & $\begin{array}{l}\text { Conners, CAPA, } \\
\text { Hypescheme }\end{array}$ & DSM IV & $53.3 \%$ \\
Dublin & 128 & $92 \%$ & $6-12(9.3 / 1.8)$ & CAPA & DSM IV & $88 \%$ \\
IMAGE & 174 & $85 \%$ & $4-14(11.7 / 3.9)$ & $\begin{array}{l}\text { Conners, CBCL, } \\
\text { ACTeRS } \\
\text { Conners, SDQ, } \\
\text { PACS }\end{array}$ & DSM IV & $80 \%$ \\
\hline
\end{tabular}

Transmission Disequilibrium Test (TDT) implemented in the UNPHASED program [Dudbridge, 2003; http://portal.litbio.org/ Registered/Menu/]. Allele-specific tests of association were calculated from the number of transmissions and nontransmission of the 2-, 4-, and 7-repeat alleles from heterozygote parents to their affected offspring for the two seasonal groups.

Significant differences between the seasonal groups were tested using the Chisquare test on the number of transmitted (T) and un-transmitted (NT) transmissions for each allele. Since there are several alleles that could show transmission ratio differences between the two seasons, we adjusted for the number of tests by permuting the data to derive an empirical distribution of $p$-values in the following way. The SOB group status for each family was permuted a total 10,000 times and the T/NT ratio and significance recalculated for each allele. We then took the most significant Chi-square value from the analysis of the various alleles, to derive the empirical distribution of maximum Chi-square values. This enabled us to determine how frequently the most significant Chi-square values occur by chance in our sample.

For the combined dataset, 95\% confidence intervals were derived using the t-test statistic (T-statistic [Mitchell et al., 2003]). The T-statistic represents the TDT information in terms of the proportion of transmitted alleles to the total number of transmissions from heterozygote parents. Under the null hypothesis of no association the proportion of the transmitted alleles to the total number of transmissions is expected to be 0.5 . The general formula for confidence intervals is then applied:

$z^{*} \sqrt{ }((\mathrm{T}(1-\mathrm{T}) /(\mathrm{M} 1+\mathrm{M} 2))$.

\section{RESULTS}

\section{Season of Birth Effect}

UK Census data over the last decade (www.statistics.gov.uk/statbase/Product.a sp?vlnk=5768) of $6,919,604$ live births during the period 1994-2004 suggests that there is no bias in the SOB for babies born in the UK. Close to $50 \%$ of live births occurs in the summer months (March to August $=50.72 \%$ ) and in the winter months (September to February = $49.28 \%)$. Since the ADHD samples are predominantly male (>95\%), we further investigated whether males were predominantly born in either the summer months or the winter months. The UK census data showed no difference in the proportions of male birth between seasons with near $50 \%$ of males being born in the summer and winter seasons.

The IMAGE sample consists of a combination of ADHD probands 
ascertained from around Europe and a subset from Israel, however we did not have access to census data from each of the different countries involved. Nevertheless, we reasoned that the Irish and UK samples would be closely similar due to geographic proximity, and this would also be the case for the majority of the IMAGE samples that were derived from Northern European countries. We therefore, looked to see if there was evidence of heterogeneity for SOB between the various countries. Since no evidence of heterogeneity for the percentage of births in each season was observed between sites ( $p=0.27)$, we considered that the UK census data would be sufficient to establish the control SOB rates for this study.

Therefore, the proportions of ADHD children born in the different seasonal groups in the four independent samples were assessed to see if they deviated from the census data (Table 2). In all four samples a numerically higher proportion of ADHD probands were born during the summer months compared to the winter months, although this difference when compared to the control census data was only significant for the London sample ( $p=$ 0.05). Combining all four datasets together we found that $54.1 \%$ of cases were born in the summer months compared to $50.72 \%$ in the census data, a small but nominally significant difference of $3.3 \%(p=0.026, O R=1.07,95 \% \mathrm{Cl}$ $1.10-1.13)$.

The number of births across all months between the UK census data and the combined ADHD datasets were inspected (Fig. 1). Overall there appears to be no clear pattern, with a small increase in the percentage of births in the ADHD sample observed for the months of May, June, and August and a small decrease during April, September, and December. In order to derive a better estimate of the significance of the SOB association with ADHD and adjust for the effect of outliers, we performed 10,000 permutations of the month of birth status for each proband and reconstituted SOB group membership based on the permutated datasets to derive an empirical significance for the association. The result was similar to the nominal observation and did not alter our conclusions ( $p=0.028)$. While a significant difference is observed for SOB and case/control status, the $p$-value is not hugely significant. This paucity of significance points to an extremely marginal effect considering the total sample size in this analysis $(6,920,716)$.

Table 2:

Comparison of the number of summer to winter births in each ADHD family data set, and the combination of all four data sets combined. Significance values compared to UK census data.

\begin{tabular}{|lccc|}
\hline Sample & Summer Births & Winter Births & Chi Square p value \\
\hline UK & $59.1 \%(\mathrm{n}=81)$ & $40.9 \%(\mathrm{n}=56)$ & 0.049 \\
Cardiff & $55.5 \%(\mathrm{n}=71)$ & $44.5 \%(\mathrm{n}=57)$ & $\mathrm{NS}$ \\
Dublin & $54.0 \%(\mathrm{n}=94)$ & $46.0 \%(\mathrm{n}=80)$ & $\mathrm{NS}$ \\
IMAGE & $52.8 \%(\mathrm{n}=354)$ & $47.2 \%(\mathrm{n}=317)$ & $\mathrm{NS}$ \\
\hline COMBINED sample & $54.1 \%(\mathrm{n}=600)$ & $45.9 \%(\mathrm{n}=510)$ & 0.026 \\
\hline
\end{tabular}


Figure 1:

Percentage of births within each calendar month, starting with January, in each of the control samples and ADHD combined sample.

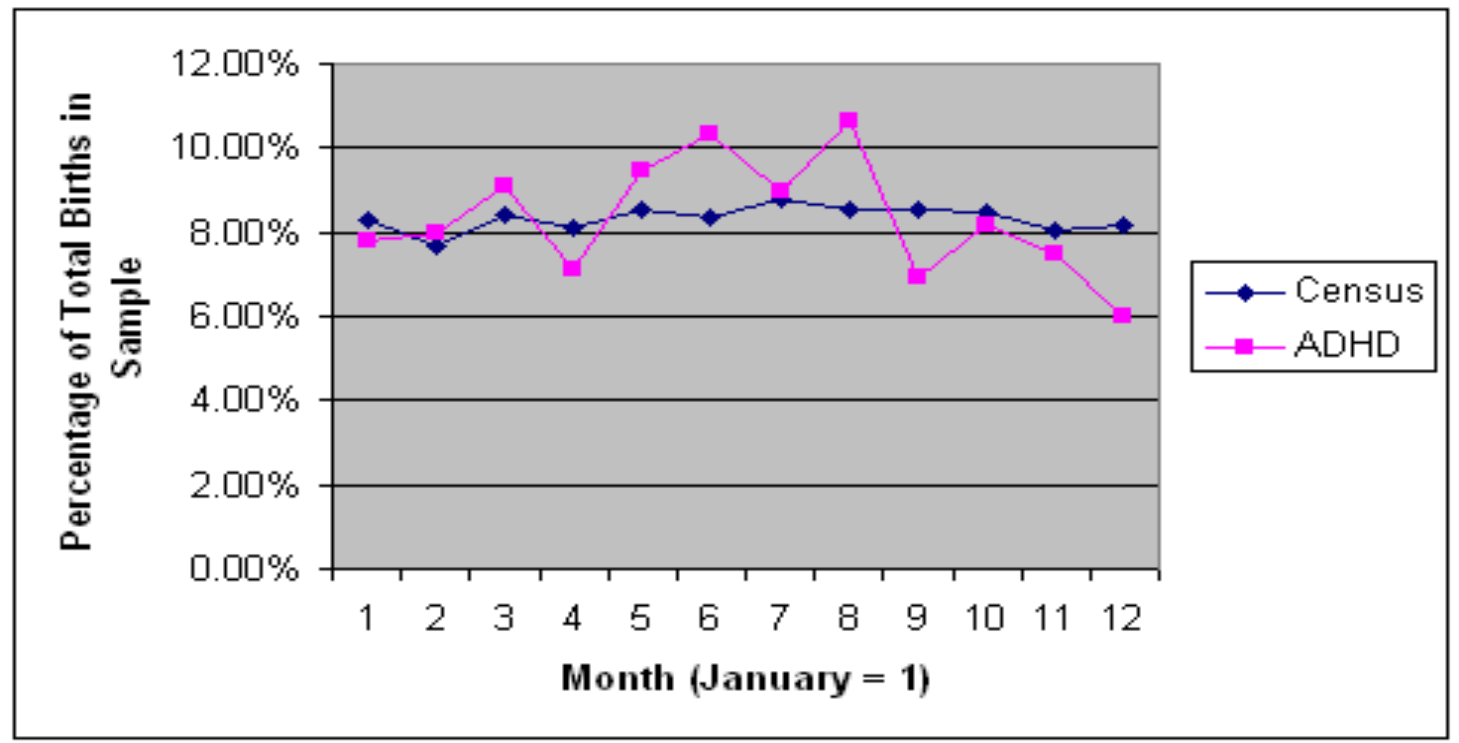

Table 3:

Transmissions of alleles of the DRD4 exon 3 VNTR to probands: No association of the marker is found in any of the samples; only when the samples are combined does the over transmission of the hypothesized risk 7-repeat allele reaches significance $(\mathrm{P}=0.04)$ with an odds ratio of 1.18.

\begin{tabular}{|c|c|c|c|c|c|}
\hline $\begin{array}{l}\text { Dataset } \\
\text { (Global P-value }\end{array}$ & Allele & $T$ & $N T$ & OR & P-value \\
\hline IOP & 2 & 18 & 17 & 1.08 & 0.87 \\
\hline \multirow[t]{2}{*}{$(P=0.20)$} & 4 & 36 & 44 & 0.9 & 0.37 \\
\hline & 7 & 29 & 22 & 1.2 & 0.33 \\
\hline Cardiff & 2 & 13 & 19 & 0.68 & 0.29 \\
\hline \multirow{2}{*}{$(\mathrm{P}=\mathbf{0 . 3 4})$} & 4 & 56 & 44 & 1.27 & 0.23 \\
\hline & 7 & 38 & 39 & 0.97 & 0.91 \\
\hline Dublin & 2 & 25 & 15 & 1.6 & 0.11 \\
\hline \multirow[t]{2}{*}{$(P=0.12)$} & 4 & 54 & 77 & 0.74 & 0.04 \\
\hline & 7 & 50 & 38 & 1.24 & 0.20 \\
\hline IMAGE & 2 & 88 & 96 & 0.92 & 0.56 \\
\hline \multirow[t]{2}{*}{$(P=0.22)$} & 4 & 271 & 293 & 0.92 & 0.35 \\
\hline & 7 & 198 & 166 & 1.19 & 0.09 \\
\hline COMBINED & 2 & 144 & 147 & 0.97 & 0.86 \\
\hline \multirow[t]{2}{*}{$(P=0.53)$} & 4 & 417 & 458 & 0.92 & 0.17 \\
\hline & 7 & 315 & 265 & 1.18 & 0.04 \\
\hline
\end{tabular}

\section{Association between ADHD and the 7-} Repeat Allele of DRD4

We re-analyzed the four datasets and the combined dataset for association between ADHD and the DRD4 VNTR (Table 3). The dataset used in this analysis had slightly lower numbers of probands than the original published reports due to the lack of date of birth information in a few cases, explaining minor differences from the original reports. The data show a small but non-significant excess transmission of the 7-repeat allele in the London, Dublin, and IMAGE datasets, which was significant in the combined dataset $(O R=1.18, p<$ 
0.04). Overall there was no global significance for the association between the DRD4 VNTR and ADHD taking all alleles into account.

\section{Interaction between SOB and DRD4}

Table 4 lists the TDT transmission ratios for each of the DRD4 alleles grouped by SOB. In addition the table displays nominal significance values of the difference in allele transmissions between the two SOB groups and the global significance values for each SOB group. In the combined datasets the overall association between the VNTR and ADHD was significant in the winter $(p=0.05)$ but not in the summer.

In each sample the transmission of the 2-repeat allele was found to be numerically higher in the summer group compared to the winter group, with overtransmission in the summer and undertransmission in the winter for all samples apart from the Dublin dataset. Undertransmission of the 2-repeat allele in the winter showed nominal significance in the London (OR $=0.3, p=0.05$ ) and combined (OR $=0.71, p=0.05)$ datasets, however over-transmission in the summer was not significant.

The difference in transmission ratios between the summer and winter groups was nominally significant for the London sample $(p=0.01)$ and for the combination of all four data sets $\left(x^{2}=6.48, p=0.01\right)$. However, the difference statistic for the 2repeat allele is one of three Chi-square values, since we also examine transmission of the common 4- and 7repeat alleles representing somewhere between two to three independent tests, and we therefore need to take into account the distribution of maximum Chisquare values under the null hypothesis of no association. Using empirical methods, we determined that the significance of an observed p-value of 0.0149 as the most extreme value, occurs approximately $19 \%$ of the time and therefore conclude that this is likely to be a chance observation.

In contrast, the 7-repeat allele showed numerically higher transmission in the winter group compared to the summer group in each of the independent samples. The over-transmission of the 7-repeat allele in the winter, but not in the summer, reached nominal significance in the combined dataset $(O R=1.33, p=$ 0.02 ). The difference in transmission ratios for the 7-repeat allele between the two SOB groups was not however significant.

The results of the analysis of the combined dataset are shown in Figure 2, illustrating the difference in transmission of the 2- and 7-repeat alleles in the SOB groups using the T-statistic, the proportion of transmitted alleles. These data show that there is a significant overtransmission of the 7-repeat allele and under transmission of the 2-repeat allele in the winter months. In contrast, in the summer months none of the alleles show a significant association with ADHD; confidence intervals on the T-statistic overlapping with the null hypothesis of 0.5 .

Examination of the combined dataset month by month shows that the evidence for increased transmission of the 2-repeat allele during summer months can be attributed to a single finding in June. Similarly, there is no clear pattern of effect for the 7-repeat allele. Due to the small number of samples in each month, the findings are "noisy" and are therefore likely to represent random sampling error rather than a true effect of SOB.

\section{DISCUSSION}

The motivation for this article came from the current interest in gene by environment interactions on risk for psychiatric disorders [Moffitt et al., 2005]. Previous articles have suggested that SOB might be associated with $A D H D$, indicating 
the influence of environmental risks showing seasonal variation, such as viral infections or number of hours exposed to sunlight [Liederman and Flannery, 1994; Mick et al., 1996]. In addition, one article reported the possible interaction between SOB with genotype of DRD4 on risk for ADHD [Seeger et al., 2004]. These previous analyses failed to reach firm conclusions due to the limited amount of data reported and discrepancies in the findings between various studies, therefore we set out to confirm or challenge these previous findings.

We have now investigated SOB variation in four independent ADHD family samples consisting of 1,110 clinically ascertained ADHD probands. We observed a small 3.3\% but significant increase in the number of ADHD probands born in the summer months compared to a large control sample of live births born in the UK from 1994 to 2004. Inspection of the month by month data did not, however,

Table 4:

Odds ratio statistics for each allele in each seasonal group.

\begin{tabular}{|c|c|c|c|c|c|c|c|c|c|c|}
\hline & \multirow[b]{2}{*}{ Allele } & \multicolumn{2}{|c|}{ Summer } & \multicolumn{2}{|c|}{ Winter } & \multirow{2}{*}{$\begin{array}{c}\text { Summer } \\
\text { (Global-p) } \\
\text { OR }\end{array}$} & \multirow{2}{*}{$\begin{array}{c}\text { Winter } \\
\text { (Global-p) } \\
\text { OR }\end{array}$} & \multicolumn{3}{|c|}{ Nominal p-values } \\
\hline & & $T$ & $N T$ & $T$ & $N T$ & & & Summer & Winter & Differences \\
\hline London & $\begin{array}{l}2 \\
4 \\
7\end{array}$ & $\begin{array}{l}15 \\
19 \\
18\end{array}$ & $\begin{array}{c}7 \\
30 \\
17\end{array}$ & $\begin{array}{c}3 \\
17 \\
11\end{array}$ & $\begin{array}{c}10 \\
14 \\
5\end{array}$ & $\begin{array}{c}(\mathrm{P}=0.48) \\
2.14 \\
0.60 \\
1.06\end{array}$ & $\begin{array}{c}(\mathrm{P}=0.068) \\
0.30 \\
1.20 \\
2.20\end{array}$ & $\begin{array}{l}0.09 \\
0.12 \\
0.87\end{array}$ & $\begin{array}{l}0.05 \\
0.59 \\
0.13\end{array}$ & $\begin{array}{c}0.009 \\
0.16 \\
0.25\end{array}$ \\
\hline Cardiff & $\begin{array}{l}2 \\
4 \\
7\end{array}$ & $\begin{array}{c}7 \\
33 \\
19\end{array}$ & $\begin{array}{c}5 \\
24 \\
24\end{array}$ & $\begin{array}{c}6 \\
23 \\
19\end{array}$ & $\begin{array}{l}14 \\
20 \\
15\end{array}$ & $\begin{array}{c}(\mathrm{P}=0.05) \\
1.4 \\
1.8 \\
0.79\end{array}$ & $\begin{array}{c}(\mathrm{P}=0.29) \\
0.43 \\
1.15 \\
1.27\end{array}$ & $\begin{array}{l}0.56 \\
0.23 \\
0.45\end{array}$ & $\begin{array}{l}0.07 \\
0.65 \\
0.49\end{array}$ & $\begin{array}{l}0.11 \\
0.66 \\
0.31\end{array}$ \\
\hline Dublin & $\begin{array}{l}2 \\
4 \\
7\end{array}$ & $\begin{array}{l}11 \\
32 \\
27\end{array}$ & $\begin{array}{c}6 \\
38 \\
22\end{array}$ & $\begin{array}{l}14 \\
22 \\
23\end{array}$ & $\begin{array}{c}9 \\
39 \\
16\end{array}$ & $\begin{array}{c}\mathrm{P}=0.2) \\
1.8 \\
0.84 \\
1.23\end{array}$ & $\begin{array}{c}\mathrm{P}=0.13) \\
1.56 \\
0.56 \\
1.44\end{array}$ & $\begin{array}{l}0.23 \\
0.47 \\
0.48\end{array}$ & $\begin{array}{l}0.30 \\
0.03 \\
0.26\end{array}$ & $\begin{array}{c}0.8 \\
0.26 \\
0.7\end{array}$ \\
\hline IMAGE & $\begin{array}{l}2 \\
4 \\
7\end{array}$ & $\begin{array}{c}56 \\
146 \\
97 \\
\end{array}$ & $\begin{array}{c}51 \\
157 \\
86 \\
\end{array}$ & $\begin{array}{c}32 \\
125 \\
101 \\
\end{array}$ & $\begin{array}{c}45 \\
136 \\
80 \\
\end{array}$ & $\begin{array}{c}(\mathrm{P}=0.21) \\
1.1 \\
0.9 \\
1.13\end{array}$ & $\begin{array}{c}(\mathrm{P}=0.27) \\
0.71 \\
0.92 \\
1.26\end{array}$ & $\begin{array}{l}0.63 \\
0.53 \\
0.42 \\
\end{array}$ & $\begin{array}{l}0.14 \\
0.50 \\
0.12 \\
\end{array}$ & $\begin{array}{l}0.15 \\
0.95 \\
0.59 \\
\end{array}$ \\
\hline COMBINED & $\begin{array}{l}2 \\
4 \\
7\end{array}$ & $\begin{array}{c}89 \\
230 \\
161\end{array}$ & $\begin{array}{c}69 \\
249 \\
149\end{array}$ & $\begin{array}{c}55 \\
187 \\
154\end{array}$ & $\begin{array}{c}78 \\
209 \\
116\end{array}$ & $\begin{array}{c}(\mathrm{P}=0.28) \\
1.29 \\
0.92 \\
1.08\end{array}$ & $\begin{array}{c}(\mathrm{P}=0.05) \\
0.71 \\
0.89 \\
1.33\end{array}$ & $\begin{array}{l}0.11 \\
0.39 \\
0.50\end{array}$ & $\begin{array}{l}0.05 \\
0.27 \\
0.02\end{array}$ & $\begin{array}{l}0.01 \\
0.82 \\
0.22\end{array}$ \\
\hline
\end{tabular}

suggest a consistent pattern and the mismatch in size of the control data to the case data means that the study is overpowered (i.e. even a small percent difference would be significant). We therefore conclude that the effect is likely to represent the effect of random sampling error and is unlikely to represent a biological mechanism.

We further investigated the interaction between SOB and DRD4 alleles and risk for
ADHD. Overall the combined dataset confirms the allele-specific hypothesis established by the results of metaanalyses of world data, for a small but significant association of the 7-repeat allele in the exon 3 VNTR with ADHD [Faraone et al., 2005]. The average odds ratio we observed is in keeping with previous published estimates. We were very interested in the pattern of findings we observed with increase transmission of 
the 2-repeat allele in the summer and decreased transmission in the winter months, which gave a nominally significant association in transmission ratios between the two SOB groups. However, since this was not an a priori hypothesis, it is appropriate to adjust for the transmission ratio differences for the three common alleles that we investigated. Inspection of the Chi-square distribution for maximum

\section{Figure 2:}

Line diagram of the T statistic, with $95 \%$ confidence intervals of the 2- and 7-repeat alleles between seasonal subsets for the combined data set.

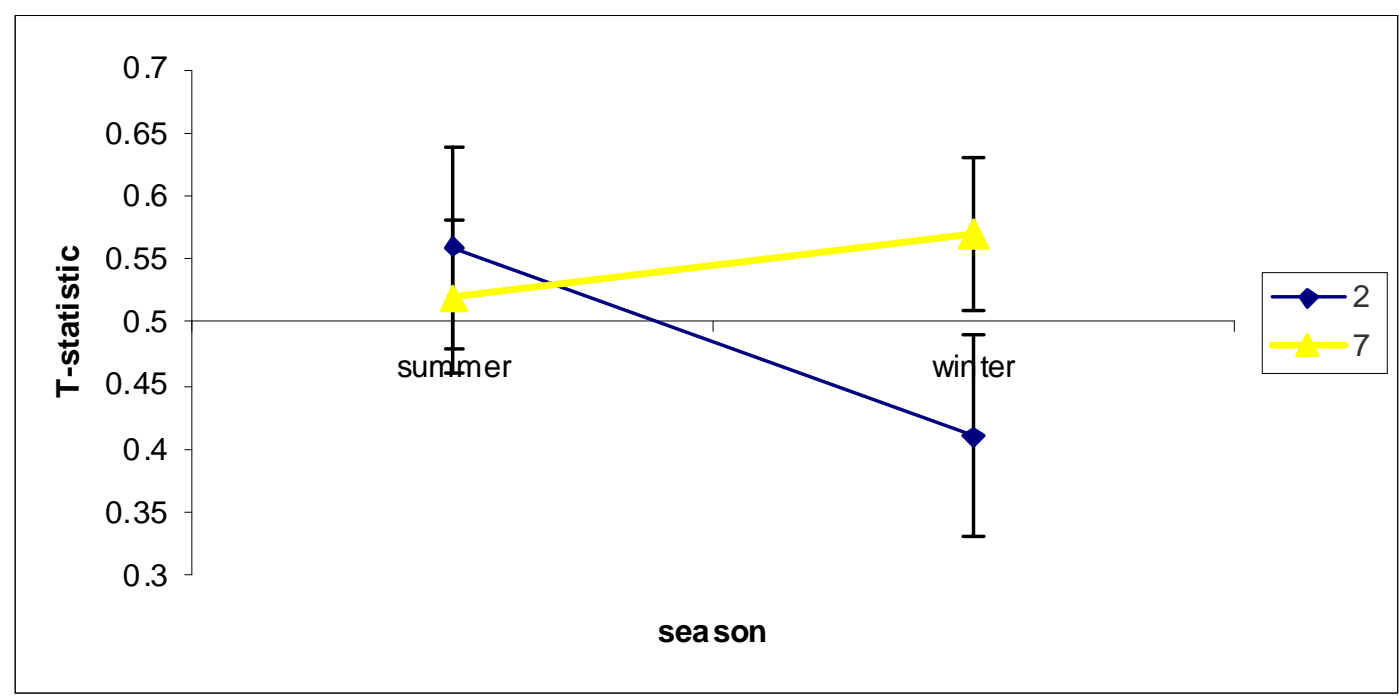

Chi-square indicated that the true significance level is around 0.19 and is therefore not worth further investigation. For the 7-repeat allele we observed significant allele-specific association in the winter but not the summer months. However this difference did not reach even nominal significance. We therefore conclude that the main observation is the previously identified over-transmission of the 7-repeat allele with no evidence for an interaction with SOB. Our data proposes the rejection of an effect of $\mathrm{SOB}$ for increased risk for ADHD.

This conclusion seems highly plausible. These data show the opposite trend to that observed by Seeger et al. [2004] who concluded that the 7-repeat allele confers risk for ADHD in those born in the summer months, whereas our data shows increased risk from the 7-repeat allele in the winter months. Furthermore, the two studies that only considered the association with SOB found opposite trends [Liederman and Flannery, 1994; Mick et al., 1996]. One limitation of this study is that we have not been able to examine the specific clinical sub-groups of ADHD described in the previous research leaving open the possibility, although unlikely, that SOB effects are restricted to clinical sub-groups. The current study utilized DSM-IV combined subtype ADHD subjects, whereas to fully replicate the findings presented in the Seeger et al. [2004] study a sample of hyperkinetic probands with comorbid conduct disorder would have to be investigated.

\section{REFERENCES}

American Psychiatric Association. 1994. Diagnostic and Statistical Manual of Mental Disorders. Fourth Edition.

Amons PJ, Kooij JJ, Haffmans PM, Hoffman TO, Hoencamp E. 2006. Seasonality of mood disorders in adults with lifetime attention-deficit/hyperactivity disorder (ADHD). J Affect Disord 91(2-3):251255 
Brookes K, Xu X, Chen W, Zhou K, Neale B, Lowe N, Anney R, Franke B, Gill M, Ebstein R, et al. 2006a. The analysis of 51 genes in DSM-IV combined type attention deficit hyperactivity disorder: Association signals in DRD4, DAT1 and 16 other genes. Mol Psychiatry 11(10):934-953.

Brookes KJ, Mill J, Guindalini C, Curran S, $\mathrm{Xu} \mathrm{X}$, Knight J, Chen $\mathrm{CK}$, Huang YS, Sethna V, Taylor E, et al. 2006b. A common haplotype of the dopamine transporter gene associated with attention-deficit/hyperactivity disorder and interacting with maternal use of alcohol during pregnancy. Arch Gen Psychiatry 63(1):74-81.

Brzezinski A. 1997. Melatonin in humans. N Engl J Med 336(3):186-195.

Chotai J, Serretti A, Lattuada E, Lorenzi C, Lilli R. 2003. Gene-environment interaction in psychiatric disorders as indicated by season of birth variations in tryptophan hydroxylase (TPH), serotonin transporter (5-HTTLPR) and dopamine receptor (DRD4) gene polymorphisms. Psychiatry Res 119(12):99-111.

Dudbridge F. 2003. Pedigree disequilibrium tests for multilocus haplotypes. Genet Epidemiol 25(2): 115-121.

Faraone SV, Doyle AE. 2000. Genetic influences on attention deficit hyperactivity disorder. Curr Psychiatry Rep 2(2):143-146.

Faraone SV, Perlis RH, Doyle AE, Smoller JW, Goralnick JJ, Holmgren MA, Sklar P. 2005. Molecular genetics of attentiondeficit/hyperactivity disorder. Biol Psychiatry 57(11):1313-1323.

Goldman BD. 2003. Pattern of melatonin secretion mediates transfer of photoperiod information from mother to fetus in mammals. Sci STKE 2003(192):PE29.

Hawi Z, McCarron M, Kirley A, Daly G, Fitzgerald M, Gill M. 2000. No association of the dopamine DRD4 receptor (DRD4) gene polymorphism with attention deficit hyperactivity disorder (ADHD) in the Irish population. Am J Med Genet 96(3):268-272.

Holmes J, Payton A, Barrett JH, Hever T, Fitzpatrick $H$, Trumper AL, Harrington $R$, McGuffin $P$, Owen $M$, Ollier $W$, et al. 2000.Afamily-based and case-control association study of the dopamine D4 receptor gene and dopamine transporter gene in attention deficit hyperactivity disorder. Mol Psychiatry 5(5):523-530.

Kahn RS, Khoury J, Nichols WC, Lanphear BP. 2003. Role of dopamine transporter genotype and maternal prenatal smoking in childhood hyperactiveimpulsive, inattentive, and oppositional behaviors. J Pediatr 143(1):104-110.

LaHoste GJ, Swanson JM, Wigal SB, Glabe C, Wigal T, King N, Kennedy JL. 1996. Dopamine D4 receptor gene polymorphism is associated with attention deficit hyperactivity disorder. Mol Psychiatry 1(2):121-124.

Li D, Sham PC, Owen MJ, He L. 2006. Meta-analysis shows significant association between dopamine system genes and attention deficit hyperactivity disorder (ADHD). Hum Mol Genet. in press.

Liederman J, Flannery KA. 1994. Fall conception increases the risk of neurodevelopmental disorder in offspring. J Clin Exp Neuropsychol 16(5):754-768.

McGrath JJ, Barnett AG, Eyles DW. 2005. The association between birth weight, season of birth and latitude. Ann Hum Biol 32(5):547-559.

Mick E, Biederman J, Faraone SV. 1996. Is season of birth a risk factor for attention-deficit hyperactivity disorder? J Am Acad Child Adolesc Psychiatry 35(11):1470-1476.

Mick E, Biederman J, Faraone SV, Sayer J, Kleinman S. 2002a. Case-control study 
of attention-deficit hyperactivity disorder and maternal smoking, alcohol use, and drug use during pregnancy. J Am Acad Child Adolesc Psychiatry 41(4):378-385.

Mick E, Biederman J, Prince J, Fischer MJ, Faraone SV. 2002b. Impact of low birth weight on attention-deficit hyperactivity disorder. J Dev Behav Pediatr 23(1):16-22.

Mill J, Curran S, Kent L, Richards S, Gould A, Virdee V, Huckett L, Sharp J, Batten C, Fernando S, et al. 2001. Attention deficit hyperactivity disorder (ADHD) and the dopamine D4 receptor gene: Evidence of association but no linkage in a UK sample. Mol Psychiatry 6(4):440-444.

Mitchell AA, Cutler DJ, Chakravarti A. 2003. Undetected genotyping errors cause apparent over-transmission of common alleles in the transmission/ disequilibrium test. Am J Hum Genet 72(3):598-610.

Moffitt TE, Caspi A, Rutter M. 2005. Strategy for investigating interactions between measured genes and measured environments. Arch Gen Psychiatry 62(5):473-481.

Naber D, Wirz-Justice A, Kafka MS. 1981. Circadian rhythm in rat brain opiate receptor. Neurosci Lett 21(1):45-50.

Reppert SM, Weaver DR. 1995. Melatonin madness. Cell 83(7):1059-1062.

Seeger $G$, Schloss $P$, Schmidt MH, RuterJungfleisch A, Henn FA. 2004. Geneenvironment interaction in hyperkinetic conduct disorder (HD + CD) as indicated by season of birth variations in dopamine receptor (DRD4) gene polymorphism. Neurosci Lett 366(3): 282-286.

Thapar A, Holmes J, Poulton K, Harrington R. 1999. Genetic basis of attention deficit and hyperactivity. Br J Psychiatry 174:105-111.

Thapar A, Langley K, Fowler T, Rice F, Turic $D$, Whittinger $N$, Aggleton J, Van den Bree M, Owen M, O'Donovan M. 2005. Catechol-O-methyltransferase gene variant and birth weight predict earlyonset antisocial behavior in children with attention-deficit/hyperactivity disorder. Arch Gen Psychiatry 62(11):1275-1278.

Tosini G, Dirden JC. 2000. Dopamine inhibits melatonin release in the mammalian retina: in vitro evidence. Neurosci Lett 286(2):119-122.

Zawilska JB, Nowak JZ. 1994. Does D4 dopamine receptor mediate the inhibitory effect of light on melatonin biosynthesis in chick retina? Neurosci Lett 166(2):203-206.

Zisapel N. 2001. Melatonin-dopamine interactions: from basic neurochemistry to a clinical setting. Cell Mol Neurobiol 21(6):605-616.

Zisapel N, Laudon M. 1983. Inhibition by melatonin of dopamine release from rat hypothalamus: regulation of calcium entry. Brain Res 272(2): 378-381.

Zisapel N, Egozi Y, Laudon M. 1983. Inhibition by melatonin of dopamine release from rat hypothalamus in vitro: Variations with sex and the estrous cycle. Neuroendocrinology 37(1):4147. 